\title{
นึิNIVERSITAS
}

Revista de Ciencias Sociales y Humanas de la Universidad Politrécnica Salesiana

https://doi.org/10.17163/uni.n32.2020.02

\section{Discusión del común multiescalar a partir del Territorio de los Pueblos Aislados ${ }^{1}$}

\author{
Discussion of the multi-scale common \\ from the Territory of the Isolated Peoples
}

\author{
Manuel Bayón Jiménez \\ Colectivo de Geografía Crítica del Ecuador \\ Facultad Latinoamericana de Ciencias Sociales \\ geomanuelbayon@gmail.com \\ Código Orcid: https://orcid.org/0000-0002-9450-9718 \\ Íñigo Arrazola Aranzábal \\ Colectivo de Geografía Crítica del Ecuador \\ Universidad Federal de Bahía \\ norpentar@gmail.com \\ Código Orcid: https://orcid.org/0000-0003-0991-3466
}

\begin{abstract}
Resumen
En las dos últimas décadas, la sociedad ecuatoriana ha tomado progresiva conciencia de los Pueblos Indígenas en Aislamiento Tagaeri-Taromenane, los últimos pueblos que hasta el momento habitan en la Amazonía ecuatoriana sin ser asimilados, el mayor reto para la pluriculturalidad y pluriterritorialidad asumida en la Constitución de Ecuador de 2018. Sin embargo, la existencia de yacimientos petroleros en el subsuelo de su territorio ha generado sucesivas ampliaciones de la frontera petrolera, incluyendo la construcción de un entramado de vías que ha propiciado una fuerte colonización agrícola. Este artículo profundiza en la historia del reconocimiento de la territorialidad de los Pueblos en Aislamiento y la defensa de la misma que se ha realizado desde la sociedad ecuatoriana, convirtiendo el Yasuní en un común territorial que ha excedido sus fronteras espaciales.
\end{abstract}

\section{Palabras clave}

Pluriterritorialidad, pueblos en aislamiento, Ecuador, Amazonía, ecologismo.

Forma sugerida de citar: Bayón Jiménez, M., \& Arrazola Aranzábal, Í. (2020). Discusión del común multiescalar a partir del Territorio de los Pueblos Aislados. Universitas, 32, pp. 37-54.

1 Este artículo es producto del conocimiento del Colectivo de Geografía Crítica del Ecuador, que integra a más personas de las que lo firmamos, en interacción con otras organizaciones y luchas por los territorios. Conocimiento adquirido en conversaciones, mapeos colectivos, viajes, y reuniones mantenidas desde 2012, vinculándose además con nuestras tesis o trabajos profesionales. Es decir, este texto es producto de la suma de reflexiones colectivas. 


\begin{abstract}
In the last two decades, the Ecuadorian society has become more aware of the reality of the TagaeriTaromenane, the last of the Isolated People living in the Ecuadorian Amazon, and the greatest challenge for the so called plurinational Ecuadorian Constitution. However, the existence of oil reserves in their space has promoted the expansion of the extractivist frontier, which created a networks of roads that promoted its successive agricultural colonization. This paper gets deeper in the history of acknowledgement of these Isolated people's rights and territoriality. Big parts of the Ecuadorian society have been involved in their defense, therefore constructing the Yasuni as a territorial common transcending its scale and spatial barriers.
\end{abstract}

\title{
Keywords
}

Pluriterritoriality, isolated people, Ecuador, Amazon, ecologism.

\section{Introducción: Los PIA ante un proceso de colonización guiado por el Estado}

Los Pueblos Indígenas Aislados (PIA) y el Estado de Ecuador se encuentran en un conflicto cuyo origen se remonta a los 500 años de colonización de la región amazónica. La colonización de esta área cobró especial intensidad a partir de la década del 60 del siglo XX, cuando grandes yacimientos de petróleo fueron encontrados en este espacio. Con el Colectivo de Geografía Crítica del Ecuador, del que formamos parte, hemos cartografiado este proceso territorial en su devenir histórico, resaltando la progresiva construcción de bloques petroleros, vías y el aumento de la deforestación generada en los espacios de vida de los pueblos waorani, taromenane y tagaeri (Maldonado \& Bayón, 2017). Hasta mediados del siglo XX estos pueblos eran estereotipados como aucas, palabra en kichwa que significa salvajes, debido a la fuerte resistencia que ofrecían a las expediciones colonizadoras que comenzaron a tratar de contactarlos en las últimas décadas del siglo XIX, si bien con resultados escasos (Álvarez, 2017). 
Las tensiones con estos pueblos hunden sus raíces en la historia colonial española y las tentativas de colonización lideradas por las diversas órdenes religiosas que consiguieron ejercer una relativa influencia sobre los principales ríos de la Alta Amazonía norte, importantes en el transporte de mercancía y en la búsqueda de oro, lo que provocó el desplazamiento de otros pueblos de los Andes a estas regiones (Wilson, Bayón \& Díez, 2015). El inicio del boom del caucho ocasionó ciclos adicionales de expansión del capital ligados con el rapto y genocidio de pueblos enteros, provocando la huida de diferentes grupos que quedaron sin contacto, situación que se mantiene hasta la actualidad (Muratorio, 1987). Estos ciclos de expansión y abandono de las actividades extractivas en la región contribuyeron hasta la década de 1950 en la construcción de la Amazonía como un "mito", según las palabras del presidente Galo Plaza Lasso. Este tipo de declaraciones tan comunes en la época mostraban al mismo tiempo el escaso control territorial por parte del Estado sobre estas áreas.

La llegada de empresas transnacionales del petróleo comenzó a partir de 1960 supuso un drástico cambio en la configuración socioespacial de la región. La instalación de Texaco a los territorios waorani fue facilitada por el contacto y reasentamiento de muchos grupos de esta nacionalidad en un protectorado a cargo del Instituto Lingüístico de Verano, organización evangélica cuya acción fue devastadora en varios países de América Latina. Este protectorado encerró literalmente a clanes completos bajo unas estrictas normas morales que incluía vestimenta, vivienda o trabajos. Constituye así un caso ejemplar de desterritorialización forzada de todo un pueblo (Almeida \& Proaño, 2008).

No obstante, las etnias Tagaeri y Taromenane no aceptaron esta manera de vincularse con las órdenes misioneras cristianas y enfrentaron el proceso de colonización arrancado por el Estado a partir de las primeras concesiones petroleras que conllevó la construcción de carreteras, la llegada de colonos (la mayoría campesinos sin tierra), la aparición de las primeras ciudades etc. Durante los últimos 50 años, el territorio de estos pueblos se ha visto reducido dramáticamente, asediados por nuevas combinaciones de bloques petroleros y un ínfimo reconocimiento de sus derechos territoriales por parte del Estado (Maldonado \& Bayón, 2017).

De manera concomitante, la sociedad civil del Ecuador ha asumido de forma paulatina un papel en la protección de estos pueblos. En 1999 se de- 
cretó la Zona Intangible Tagaeri-Taromenane (ZITT) para los PIA, viéndose ampliada en $10 \mathrm{~km}$ su área de amortiguamiento ocho años más tarde (De Marchi et al., 2011). De igual manera, la aparición de legislación internacional tal y como el convenio 169 de la Organización Internacional del Trabajo en la década de los 90, la Declaración de los Pueblos Indígenas en el las Naciones Unidas en 2997 y el reconocimiento explícito de los PIA en la Constitución del Ecuador del 2008 representa la cristalización de los esfuerzos de protección gestados durante años. En 2007, se inició también una campaña para poder dejar el petróleo del bloque 43 bajo tierra a cambio de una retribución internacional. Esta iniciativa fue el resultado de la presión y el trabajo de los grupos organizados de la sociedad civil que durante años habían defendido la biodiversidad y el respeto a la presencia de los PIA en este espacio (CMCTF, 2014).

En 2013, el gobierno derogó la iniciativa Yasuní-ITT en mensaje por televisión del entonces presidente Rafael Correa, comunicando que abría el área para su explotación petrolera. Este anuncio generó movilizaciones de nuevo tipo en la historia del país, en las que grupos de personas urbanas - especialmente jóvenes - tomaron protagonismo en las marchas y recolección de firmas para la convocatoria de una consulta popular sobre la explotación del petróleo en el Parque Nacional Yasuní. En el calor de estas movilizaciones nació Yasunidos, grupo paradigmático de este nuevo proceso de concientización ecológica vivido en el Ecuador. Finalmente, la consulta no se celebró debido a que el Consejo Nacional Electoral invalidó el proceso, a pesar de las numerosas denuncias de fraude por parte de la sociedad civil. Pese a esto, sin embargo, el Yasuní ha logrado tornarse en un símbolo global a raíz de la iniciativa Yasuní-ITT en un primer momento y más tarde debido al activismo nacional e internacional de Yasunidos en su defensa (Paredes, 2016). De esta manera, el Yasuní se ha constituido como un común que trasciende sus propios límites espaciales, en tanto que propuesta concreta para reorientar las prioridades de la economía y no destruir los espacios de vida de los PIA (Colectivo de Geografía Crítica del Ecuador, 2018). 


\section{Mapa 1}

\section{Territorio de los PIA, Waorani, PNY y Bloques Petroleros}

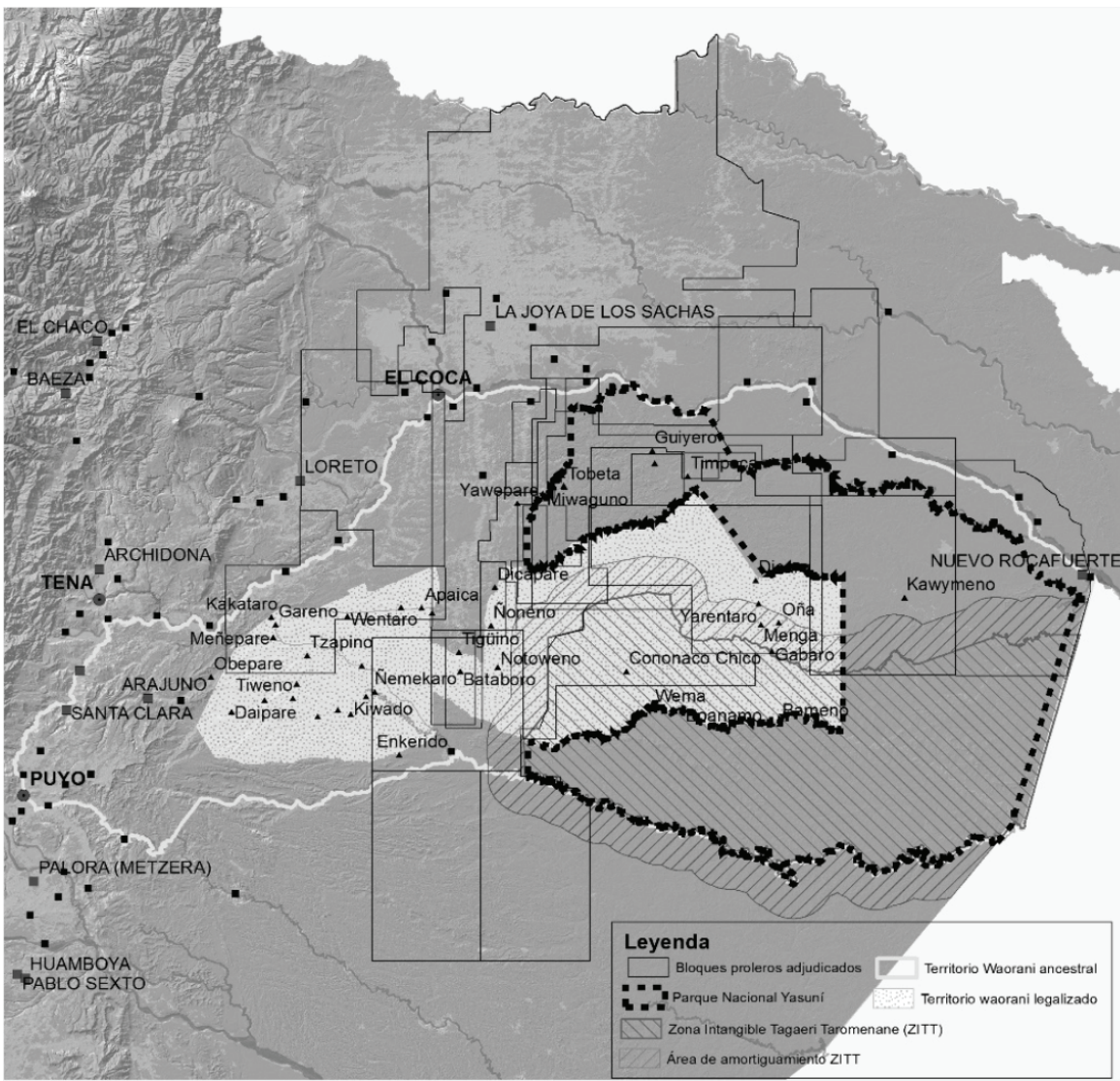

Elaboración de Paola Maldonado (2017)

\section{Las disputas por el territorio en América Latina en tanto que monopolio del Estado}

Históricamente, el territorio es concebido a partir del Estado moderno que surgió en Europa. El territorio es un elemento central en la constitución del Estado dado que sirve para delimitar el ejercicio exclusivo de poder por 
parte de este último dentro de sus dominios (Benz, 2010). Para Foucault, en la aparición del Estado moderno:

El soberano del territorio se había convertido en arquitecto del espacio, disciplinado, pero también y casi al mismo tiempo en regulador de un medio en el cual no se trata tanto de fijar los límites y las fronteras o de determinar emplazamientos como, sobre todo y esencialmente, de permitir, garantizar asegurar distintos tipos de circulación. (Foucault, 2006, p. 45)

Esto marca la forma por la que el capitalismo y la territorialidad del Estado iban a retroalimentarse en un proceso que termina por generar los Estados-nación del capitalismo mercantil.

Según Foucault, el proceso de conformación de la "gubernamentalidad" a partir del mercantilismo tuvo como ingredientes fundamentales a la economía política en tanto que saber, a los dispositivos de seguridad en tanto que instrumentos técnicos y al conjunto de personas localizadas en un territorio. Este proceso terminó con la conformación del Estado moderno en el siglo XVII (Foucault, 2007, p. 213). Estos Estados surgieron a partir de proyectos homogenizadores que implicaban una colonización hacia afuera y hacia adentro, por lo que desde la teoría crítica latinoamericana comenzaron a ser considerados como estados territoriales modernos-coloniales (Porto Gonçalves, 2009, p. 126). Los procesos de descolonización de las metrópolis europeas llevarían a la creación de los Estados-nación a lo largo del continente americano.

Los conflictos entre metrópolis y colonias, representadas por las élites criollas descendientes de los europeos, dieron lugar a un proceso de autodeterminación que terminó por generar nuevos Estados territoriales en el siglo XIX. No obstante, estos Estados no sufrieron un proceso de descolonización de las estructuras de poder mediante las que habían sido configurados. Más bien, éstas fueron adaptadas a los nuevos contextos nacionales. Todo esto implicó que las otras formas de ejercer territorialidad — las de los pueblos indígenas, negros o campesinos - fueron sistemáticamente negadas hasta prácticamente comienzos del siglo XXI. Es posible percibir estas territorialidades desde varios puntos de vista. Desde una perspectiva más simbólica, "territorio es espacio apropiado, espacio hecho cosa propia, en definitiva, el territorio es instituido por sujetos y grupos sociales que se afirman por medio de él" y, por tanto, "hay, siempre, territorio y territorialidad, o sea, procesos sociales de territorialización" (Porto Gonçalves, 2009, p. 127). Porto 
Gonçalves lo teoriza como una triada "território-territorialidade-territorialização" (2002, p. 230).

Desde una perspectiva que concibe el ejercicio de territorialidades múltiples, Haesbert observa al territorio como el desenvolvimiento de esos otros poderes que no emanan del Estado. El enfoque de este geógrafo brasileño también se vincula con la apropiación simbólica del espacio no articulados en torno al Estado:

Territorio, por lo tanto, en cualquier acepción, tiene que ver con poder, pero no apenas el tradicional 'poder político'. Se refiere tanto al poder en el sentido más concreto, de dominación, cuanto al poder en el sentido más simbólico, de apropiación. Lefebvre distingue apropiación de dominación ("posesión', 'propiedad'): el primero consiste en un proceso mucho más simbólico, cargado de las marcas de lo 'vivido', del valor de uso; el segundo más concreto, funcional y vinculado al valor de cambio [...] Podemos entonces afirmar que el territorio, inmerso en relaciones de dominación y/o apropiación sociedad-espacio, se prolonga [...] a lo largo de un continuum que va desde la dominación político-económica más 'concreta' y 'funcional' a la apropiación más subjetiva y/o ‘cultural-simbólica’. (Haesbaert, 2008, p. 20; traducción libre del Colectivo de Geografía Crítica)

En opinión de este autor, las dinámicas de apropiación del espacio son vistas como procesos de territorialización. Estos procesos de (re)territorialización son diversos y responden a los múltiples poderes que confluyen en el espacio desde diferentes ámbitos y orígenes (Haesbaert, 2007, p. 22). Asimismo, Haesbert defiende la importancia de tener en cuenta la enorme variación histórica y geográfica de estas dinámicas de apropiación espacial: "obviamente territorializarse para un grupo indígena de la Amazonía no es lo mismo que territorializarse para los grandes ejecutivos de una empresa transnacional" (2007, p. 97).

Los reclamos por parte de los grupos subalternos por su derecho a ejercer sus propias formas de apropiación del espacio fueron tomando forma en torno a lo que terminó por concebirse como "derechos territoriales", también considerados como "las fronteras indígenas de la globalización" (Toledo, 2005, p.67). En las últimas dos décadas del siglo XX, los alzamientos de los pueblos indígenas en América Latina tuvieron como consecuencia el reconocimiento de sus derechos territoriales en varios países (Toledo, 2005, p.86). Es paradójico no obstante que el reconocimiento de estos derechos 
provenga de un Estado-nación inmerso cada vez más en una globalización propia de la evolución de las últimas etapas del capitalismo en la que la financiación de la economía y las ciudades globales parecen reconfigurar drásticamente los arreglos espaciales previos.

Esta paradoja se concibe mejor a través de la contradicción intrínseca a esta etapa de desarrollo territorial del capitalismo. La globalización económica provoca una reconfiguración socioespacial de los mecanismos de acumulación que colocan formidables obstáculos a la hora de pensar en proyectos de autonomía viables para los pueblos que logren garantías sus derechos territoriales. Esta ofensiva provoca una enorme ola de resistencias frente al avance del capital en estos espacios a través de los megaproyectos, las tentativas de bioprospección, la explotación minera o de hidrocarburos etc. (Toledo, 2005).

En los trabajos y reflexiones como Colectivo de Geografía Crítica, hemos encontrado de gran utilidad la categoría de (des)ordenamiento territorial para entender el papel del Estado en todos estos procesos. Este concepto ofrece una mirada crítica sobre la tan manida propuesta de ordenamiento territorial impulsada desde el Estado, supuestamente el único actor con legitimidad de realizar tal tarea en el territorio. La idea de (des)ordenamiento territorial es elaborada desde el punto de vista de los más afectados por la explotación de sus espacios de vida y procura poner de relieve que el ordenamiento pretendido por el Estado se vincula necesariamente con su opuesto, el desordenamiento, que implica la ruptura de los otros arreglos espaciales de pueblos y comunidades debido a la imposición de la malla territorial estatal (Guerra, 2003).

\section{El desordenamiento capitalista tras la Constitución plurinacional-territorial}

La Constitución del Ecuador fue promovida con el triunfo de Rafael Correa en las urnas en 2006. Esta constitución se inscribe en el paradigma jurídico conocido como neoconstitucionalismo, basado en enfoques plurales y garantistas que subrayan la importancia de los derechos fundamentales (Prieto Sanchís, 2009). Los derechos indígenas, incluidos los derechos territoriales, adquieren una doble dimensión, individual y colectiva, al paraguas del neoconstitucionalismo (Ávila, 2008, p. 44). Por su vez, el pluralismo hace de garantía al reconocimiento de los derechos fundamentales de 
manera no homogenizante. Toma como punto de partida varias fuentes de derecho y no sólo el Derecho Romano. Identifica también tres dimensiones de estos derechos fundamentales para los pueblos: 1) el derecho al auto-gobierno; 2) derecho especial de representación y 3) derechos poli-étnicos" (Porto Gonçalves, 2009, p. 128).

El texto constitucional ecuatoriano cuenta con un gran mosaico de derechos territoriales indígenas amparados en el Convenio 169 de la OIT y la Declaración de la ONU sobre Pueblos Indígenas. Colocan de manera particular los derechos de los PIA en su artículo 57, a través del cual se prohíben explícitamente las actividades extractivas y se reconoce su derecho de autogobierno.

Los territorios de los pueblos en aislamiento voluntario son de posesión ancestral irreductible e intangible, y en ellos estará vedada todo tipo de actividad extractiva. El Estado adoptará medidas para garantizar sus vidas, hacer respetar su autodeterminación y voluntad de permanecer en aislamiento, y precautelar la observancia de sus derechos. La violación de estos derechos constituirá delito de etnocidio, que será tipificado por la ley. (Art. 57, Constitución de la República del Ecuador)

Con todo, no se ha llevado a cabo la puesta en marcha de medidas concretas para su efectiva protección. El proceso de cercamiento sobre los PIA en los últimos tiempos ha expandido el conflicto territorial de estos pueblos. Hoy en día los conflictos se centran en la zona noroccidental de la ZITT, en sus límites exteriores, en el área de avance de la extracción petrolera de los bloques Armadillo, 14 y 17 (Maldonado \& Bayón, 2017). El capital, con la facilitación del Estado, impone el ejercicio de su territorialidad a través del avance de la extracción del crudo mientras que las formas de protección de los pueblos y la naturaleza quedan subordinadas. El derecho de los pueblos waorani a ejercer su territorialidad se ve también relegado y esto, junto con la limitación reciente de la ZITT por las actividades extractivas coloca en peligro su supervivencia y la de los PIA. Hay evidencias ya de hecho de que las vías construidas han provocado una fuerte dinámica de colonización (Maldonado \& Bayón, 2017).

En el mapa de a continuación se pueden apreciar las formas por las que el (des)ordenamiento territorial hace que no se cuenten con acciones efectivas para proteger el espacio de vida de los PIA. El mapa ilustra también la gran cantidad de ataques y enfrentamientos en la ZITT que evidencian este punto. 


\section{Mapa 2 \\ Registro de incidentes con Pueblos Indígenas Aislados e infraestructura petrolera}

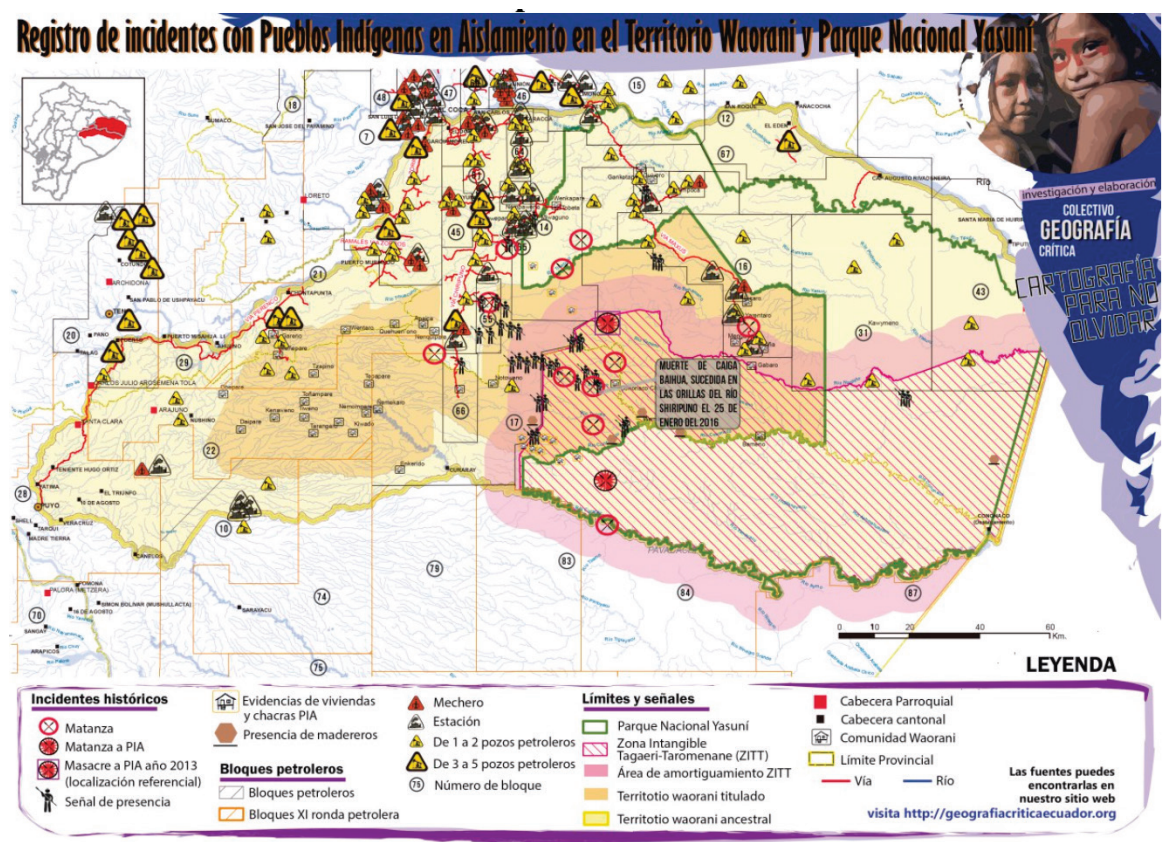

Elaboración: Paola Maldonado y Braulio Gutiérrez (2017)

En agosto de 2014, la cancelación de la Iniciativa Yasuní-ITT implicó generar una nueva agresión a la parte noreste del territorio de los PIA al interior del PNY, donde el Ministerio de Ambiente del Ecuador ha aprobado perforar las Plataformas Ishpingo A y B, a escasos 300 metros de la Zona de Amortiguamiento de la ZITT, con propuestas de efectuar en el área Sísmicas Petroleros a escasos 5 kilómetros de donde están documentadas sus casas (Bayón et al., 2017).

La invasión petrolera del Parque Nacional Yasuní en el Bloque 43-ITT comenzó en 2018 con la apertura de las plataformas Tambococha. Cuando la Iniciativa Yasuní-ITT fue cancelada y se generó una promesa de explotación territorial de solo el 1x1000, el Colectivo provocó un amplio debate sobre el territorio en relación a la explotación petrolera, denunciando el falaz argumento de que solo se explota lo que se deforesta y aportando elementos 
científicos y comunicativos para develar esta falacia territorial del Gobierno de Ecuador (Colectivo de Geografía Crítica del Ecuador, 2014).

La Constitución del Ecuador es clara en su prohibición de promover nuevos espacios petroleros en el territorio de los PIA. El garantismo jurídico neoconstitucional y el pluralismo jurídico no están actuando como freno para un Estado liberal que reclama para sí el subsuelo como Estado nación en su afán de explotar el petróleo del Yasuní. El bien nacional pasa a estar por encima de los derechos indígenas sobre sus territorios y los PIA desaparecen de la política pública referida a sus territorios (CMCTF, 2014).

\section{EI Yasuní como un común territorial multiescalar en disputa}

En primer lugar, los comunes permiten observar las relaciones sociales más allá de la dicotomía entre Estado y mercado para analizar la riqueza social: su producción, distribución y reproducción. Por ello, los comunes han supuesto un referente para la formulación de nuevos paradigmas emancipatorios que salgan de dicha dicotomía (Laval \& Dardot, 2015). Este boom de los comunes ha generado el análisis y la construcción de formas alternativas de búsqueda de alternativas a los dogmas neoliberales, que a lo largo de su globalización quieren imponer la competitividad y el mercado capitalista como forma única de relación social (Colectivo de Geografía Crítica, 2018).

Aunque hay múltiples puntos de vista en relación a la concepción y alcances de los comunes, establecemos de acuerdo a Hardt y Negri (2011) así como a Laval y Dardot (2015) como primer principio considerar al común como una alternativa para pensar las relaciones sociales más allá de la propiedad en la regulación de los procesos de producción, redistribución y reproducción de la riqueza social. Esto hay que encuadrarlo en las actuales condiciones del desarrollo histórico del capitalismo tardío, no como una propuesta transhistórica. Supera así la dicotomía entre propiedad pública y privada, que ha supuesto un obstáculo en el pensamiento emancipador, al posicionar a los individuos o a un pueblo difuso como sujetos preexistentes al establecimiento de una forma de gobernar lo común. Por ello, esta propuesta a partir de lo común no va a entrar tanto en la disputa de lo privado o lo público, como en transformar las relaciones sociales que emanan de las prácticas, normas e instituciones que se encuentran en la base del funcionamiento del capital y el Estado. Por ejemplo, no propone tanto destruir o 
cuestionar el Estado en su multiplicidad de formas, como comunalizar el Estado, y esto solo puede hacerse más allá de la democracia liberal representativa y sus límites (Hardt \& Negri, 2011; Laval \& Dardot, 2015).

Como Colectivo de Geografía Crítica, nuestra mirada busca comprender los comunes desde una mirada territorial. Para analizar el rol del espacio en el cercamiento de estos, hay que comprender el territorio no como un contenedor que supone la base espacial de los procesos. Además, la forma en la que se producen los cercamientos de los comunes tienen un claro despliegue en mecanismos de control y significación territorial que van a estar en el centro de la disputa, buscando subordinar a actores sociales y privatizar lo común (Sevilla Buitrago, 2015). Por ello, los cercamientos de los comunes son analizados como una erosión de los mecanismos que buscan crear cadenas de territorios de equivalencia: desproveer al espacio social de aquellas relaciones sociales propias del común para convertirlo a la racionalidad abstracta que brinda a los mecanismos de mercado mayor control, también los vinculados al Estado. Por otro lado, los cercamientos de los comunes son procesos que promueven formas concretas de mercantilización y dominio en clave netamente espacial. Sevilla Buitrago hace hincapié respecto a los mecanismos de dominación del espacio analizados en los cercamientos de los comunes que van a estar vinculados a los regímenes regulatorios de un espacio-tiempo concreto. Como resultado, estos mecanismos de dominación y las lógicas que constituyen dependen del espacio-tiempo en el que se instauran, insertas en procesos de desarrollo geográfico desigual que van a concretar formas diferentes (Sevilla Buitrago, 2015).

El Yasuní, como uno de los casos más importantes y continuados en el Colectivo de Geografía Crítica del Ecuador, fue también parte de nuestra cartilla "Territorio y comunes: Utopías y desafíos", inscrita en "Geografiando para la Resistencia: hacia un Atlas Crítico del Ecuador", en los que el colectivo ha analizado más de treinta conflictos territoriales en los que hemos tenido algún involucramiento. El Yasuní lo enunciamos como un "común multiescalar" por la forma en la que es considerado un común y es disputado en múltiples escalas. La lectura del caso del Yasuní en tanto que común espacial presentada a continuación consiste en dos elementos analíticos principales. En primer lugar, realizaremos un esbozo de los mecanismos mediante los cuales orbitan los procesos de dominación y resistencia espacial en diversas escalas. Seguidamente, daremos cuenta del conjunto de sentidos 
y significados puestos en juego en las tentativas de explotación y los y procesos de resistencia asociados.

Las comunidades orientan sus estrategias para mantener su territorio como común fundamental. Las comunidades y pueblos amazónicos presentes en el conflicto por la extracción del crudo en el Yasuní comparten el hecho de que su territorio es la base de su reproducción, tanto material como simbólica. Analizamos también las formas y mecanismos de control espacial que despliegan se vinculan a las formas de mantenimiento de la propiedad colectiva del espacio y a las formas mediante las que deciden colectivamente sobre los usos del mismo, como, por ejemplo, los acuerdos sobre la entrada y salida o la pertenencia de la cacería encontrada. Respecto a los PIA no conocemos sus mecanismos en detalle, pero es evidente que el territorio es aún más esencial en términos materiales para su reproducción, también en términos simbólicos. Múltiples estudios han demostrado que coexisten en el Yasuní al menos dos grupos de PIA, donde la forma de ocupar el territorio es a partir de una gran vivienda comunitaria o maloka, que tiene un tiempo de uso limitado en lógicas de seminomadismo, y con una alimentación que combina la cacería, con la recolección y el cultivo de chakras (Rival, 1992).

En cuanto a los actores, dentro de su disparidad en cuanto a su composición, comparten la búsqueda de estrategias para ganar control sobre el territorio de estas comunidades. La actividad petrolera conlleva para el caso analizado mecanismos asociados a la extracción y distribución del crudo que suponen la construcción de infraestructura militar y la presencia del ejército para actuar rápidamente ante cualquier negativa de las comunidades. Sin embargo, también hay formas de ejercer el dominio menos explícitas, que se manifiestan en la plasmación de centros comunales, escuelas, canchas, centros de acopio y otras inversiones propias del Estado. Este tipo de obras, junto con la promesa de generación de empleo local, son ofrecidas para comprar el consenso local. Así, estos mecanismos mediante los que se ejerce viabilizan la actividad petrolera y la dotan de formas socioespaciales concretas.

Como ya ha sido remarcado anteriormente, estas estrategias se desenvuelven en escalas que van más allá de lo local: las empresas y el Estado desempeñan un papel muy activo a la hora de tratar de presentar la extracción del petróleo como legítima, responsable con el medio ambiente y con los PIA invocando entre otras cosas al mito de la tecnología de punta - y como asunto de interés nacional. Por otro lado, grupos ecologistas, tanto en el ámbito nacional como en el internacional, han tratado de reforzar las estrategias e inte- 
reses vinculados a la no extracción del crudo. La Iniciativa Yasuní-ITT, que permitía dejar el petróleo bajo tierra a cambio de una compensación internacional fue gestada entre movimientos ecologistas ecuatorianos y de otros países para posteriormente ser apropiada y abandonada por el Estado. El grupo Yasunidos represente otro ejemplo de este tipo. Este grupo consiguió aglutinar las sensibilidades de una población en su mayoría joven y urbana en contra de la devastación socioambiental que supondría la explotación del crudo. Los Yasunidos protagonizaron la solicitud de una consulta popular sobre la extracción en el Yasuní con recogidas de firmas y apoyos por todo el país, finalmente truncada por el gobierno (Silveira, Bayón \& Moreano, 2019).

Respecto a las significaciones, los diferentes actores se encuentran en una posición dialéctica donde las desiguales relaciones van a plasmar formas de resistencia, pero también de acuerdos. Las comunidades viven unas fuertes desigualdades internas y externas que se van a concretar en diferentes formas de entender la respuesta a la explotación petrolera y la colonización agraria en sus territorios. Pero en los PIA, esa disrupción del espacio y las posibilidades de negociación de los agentes estatales y capitalistas van a implicar una prohibición explícita en la Constitución del Ecuador y todos los acuerdos internacionales. El no contacto como parte del derecho a la autodeterminación, y la manifestación de no entrada a su territorio mediante avisos y asesinatos cuando su común territorial es agredido.

Dentro de la nacionalidad waorani hay también una multiplicidad de posturas que tienden a dividirse en dos, muy confrontadas: adaptarse a la economía petrolera para poder obtener algún beneficio de la misma (las empresas dan trabajos y compensaciones a las comunidades que tienen que dar su aprobación para la explotación petrolera), mientras que la minoritaria es contraria a la extracción y plantea potenciar las actividades turísticas. Las divisiones provocadas por la extracción del crudo han ocasionado que las asociaciones intercomunitarias estén más debilitadas, donde la organización que agrupa a todas ellas, la NAWE, se haya convertido en una disputa creciente entre las comunidades. Sin embargo, en las dos visiones de desarrollo petrolera y turística, el territorio es fundamental como común: la selva se entiende como el elemento a defender, ya sea para una negociación petrolera o como fuente de vida para el futuro.

También se han dado fuertes reconfiguraciones en el aparato del Estado y del mercado en la explotación petrolera, dado que ha considerado mejor estrategia de avance en los nuevos enclaves petroleros la promoción de una 
empresa pública ecuatoriana: Petroamazonas. Esta nueva empresa ha sido un elemento fundamental para cooptar dirigencias comunitarias en toda la Amazonía, también en la nacionalidad waorani, con quienes existe una relación conflictiva, pero donde las dádivas han limitado el cuestionamiento de la explotación petrolera en las comunidades aledañas a la misma. Entendemos que tanto esta empresa como el Estado tratan de construir el área del Yasuní, al igual que muchas otras áreas de extracción petrolera o minera, como áreas de sacrificio (Silveira et al., 2016). Este proceso de significación trata de hacer tolerable los efectos de la explotación — negados o minimizados por otra parte- en pro de un bien más amplio, del interés de la nación. Se trata de una lógica que prioriza el valor de cambio y que construye semióticamente unos territorios $-\mathrm{y}$ los seres que los habitan - jerárquicamente, por debajo de un espacio formal más abstracto situado en la escala nacional.

Por último, en la escala nacional, los colectivos contrarios a la explotación petrolera que provienen del ecologismo social como Yasunidos o Acción Ecológica arrojaron sentidos y significados diferentes sobre los espacios que tratan de defender. A lo largo proceso de movilización popular comentado anteriormente que este grupo lideró se pudo constatar como la gran biodiversidad del Yasuní lo colocaban como una suerte de "paraíso natural amenazado" a los ojos de gran parte de la población joven y urbana que secundó su no explotación. La gama de sensibilidades y emotividades proyectadas sobre este espacio parten por tanto de una posicionalidad bien diferente dado que no es un espacio de vida imprescindible para su reproducción material, sino un común que proyecta una forma de entender los derechos, la democracia y la búsqueda de un horizonte post-capitalista. Estas diferencias en la posición ocupada comunidades, activistas y Estado-mercado provocaron ocasionalmente algún debate sobre la legitimidad de los actores que, aliados y trabajando por un objetivo compartido, hablan en nombre del Yasuní.

A partir de lo anterior podemos lanzar algunas claves para pensar al Yasuní en su dialéctica de cercamiento/construcción del común multiescalar. El Yasuní en su dimensión material y simbólica es un común para los pueblos que lo habitan en su reproducción social. A nivel local, existe estas comunidades entraban complejas disputas con las empresas petroleras que, sin embargo, enarbolan sus estrategias en escalas más amplias. El Estado por su parte, proclamando su legitimidad en nombre del Bien Común para toda la nación, trata de hacer que la extracción del crudo en el Yasuní sea interpretada por la opinión pública como necesaria y responsable en términos 
ambientales y sociales. En la escala trasnacional, los grupos y movimientos ecologistas también han mostrado su capacidad para tejer alianzas y movilizar apoyos para la protección del eco-sociosistema. Por ello, el Yasuní está en disputa como común, y esta afirmación debe ser observada en múltiples escalas. De esta manera, el propio significado de lo común se teje en un proceso multiescalar contradictorio entre los diferentes actores que participan del proceso de su construcción y despojo.

\section{Conclusiones}

La colonización promovida por el Estado y por la expansión capitalista a lo largo de la historia reciente de la Amazonía ha configurado el territorio de los PIA como un espacio de fuertes tensiones, en la que han buscado mantener su territorio frente a agresiones externas. El liberalismo post-independencia con el que el Estado-nación ecuatoriano ha desarrollado su política choca con los principios constitucionales desde 2008 respecto a la plurinacionalidad, pluriterritorialidad y ejercicio de la autodeterminación que también ha sido reconocido en declaraciones internacionales relativas a los territorios indígenas.

Las tensiones territoriales producidas en el Yasuní, hogar de los PIA, ha generado una conflictividad de fuerte visibilidad social, que ha motivado que se convierta en común territorial multiescalar, dado que existen diferentes actores en relación: las comunidades locales en aislamiento y con distintas antigüedades en su colonización, las instituciones del Estado en sus distintos niveles, colectivos ecologistas de ámbito nacional con el apoyo de la lucha internacional contra el cambio climático, y un capital nacional rentista sustentado en las inversiones internacionales de las trasnacionales petroleras. Estas visiones se disputan la visión futura del espacio amazónico.

Este modelo multiescalar no es un ejemplo netamente aplicable a otros espacios donde la no presencia de PIA implica formas de dialéctica de territorialidades menos extremas: su derecho de autodeterminación y no contacto implica formas de hegemonía territorial muy distintas para empresas y Estado. Pese a ello, este artículo permite analizar las colisiones de derechos a través de la ampliación de la frontera petrolera como emblema de la territorialización del capital, que encuentra límites en la disputa multiescalar del común, en especial la protagonizada por los pueblos indígenas se mantienen aislados de los mecanismos más refinados de las empresas y el Estado para subordinar los territorios a su racionalidad. 


\section{Bibliografía}

Almeida, A., \& Proaño J. (2008). Tigre, águila y Waorani, una sola selva, una sola lucha: deuda ecológica de las transnacionales petroleras con el pueblo Waorani y el Parque Nacional Yasuní. Quito: Acción Ecológica.

Álvarez, K. (2017). Con ellos dentro: un siglo y más de continuo exterminio. En Ramiro Ávila e Ivette Vallejo (Eds.), El último grito del jaguar. Quito: Abya-Yala.

Ávila, R. (2008). Ecuador: Estado constitucional de derechos y justicia. En Ramiro Ávila (Ed.), La Constitución del 2008 en el contexto andino (pp. 19-71). Quito: Ministerio de Justicia y Derechos Humanos.

Bayón, M., Ramírez A., Moreano, M., Gutiérrez B., \& Zaragocin S. (2017). Límites territoriales a la explotación petrolera en Ishpingo y Tambococha. Recuperado de: https://bit.ly/2OzosIz (2018-05-31).

Benz, A. (2010). El Estado moderno. Fundamentos de su análisis politológico. Madrid: Centro de Estudios Políticos y Constitucionales.

Bonilla, O., Maldonado P., Silveira, M., \& Bayón, M. (2016). Nudos territoriales críticos en Ecuador: dinámicas, cambios y límites en la reconfiguración territorial del Estado. Revista Geographos, 84, marzo.

Borja, J. (2004). Los derechos en la globalización y el derecho a la ciudad. Fundación Alternativas. Recuperado de: https://bit.ly/2SqLVge (2013-11-20).

Colectivo de Geografía Crítica del Ecuador (2018). Geografiando para la resistencia. Utopías y desafios. Quito: Colectivo de Geografía Crítica del Ecuador.

Colectivo de Geografía Crítica del Ecuador (2014). Manifiesto en Defensa del Yasuní. Recuperado de: https://bit.ly/2up7Ex9 (2018-05-31).

De Marchi, M., Pappalardo, E., \& Ferrarese, F. (2011). Zona Intangible Tagaeri Taromenane (ZITT): ¿una, ninguna, cien mil? Quito: CICAME-Fundación Labaka.

Foucault, M. (2006). Seguridad, territorio, población: Curso en el Collège de France: 1977-1978, I ed. Buenos Aires: Fondo de Cultura Económica.

Foucault, M. (2007). La gubernamentalidad. En Ensayos sobre biopolítica. Argentina: Paidós.

Guerra, E. (2003). Terras Indígenas e Desordenamento Territorial. Ponencia del Encuentro de Geógrafos de América Latina (EGAL).

Haesbaert, R. (2007). Território e multiterritorialidade: um debate. GEOgraphia Revista da Pós Graduação em Geografia da Universidade Federal Fluminense, IX(17), 19-45, junho.

Haesbaert, R. (2008). O mito da desterritorializção: do "fim dos territórios" á multiterritorialidade. $3^{\circ}$ ed. Rio de Janeiro: Bertrand Brasil. 
Hardt, M., \& Negri, A. (2011). Commonwealth. El proyecto de una revolución del común. Madrid: AKAL.

Laval, C., \& Dardot, P. (2015). Común: ensayo sobre la revolución en el siglo XXI. Barcelona: GEDISA

Maldonado, P., \& Bayón, M. (2017). Nacionalidad waorani, tagaeri y taromenani: una historia de permanente acoso territorial. En Ramiro Ávila e Ivette Vallejo (Eds.), El último grito del jaguar. Quito: Abya-Yala.

Muratorio, B. (1987). Rucuyaya Alonso y la historia social y económica del Alto Napo 1850-1950. Quito: Abya-Yala.

Porto-Gonçalves, C.W. (2002). Da geografia às geo-grafias: um mundo em busca de novas territorialidades. En La guerra infinita. Hegemonía y terror mundial. Buenos Aires: CLACSO.

Porto-Gonçalves, C.W. (2009). De saberes y de territorios: diversidad y emancipación a partir de la experiencia latino-americana. Revista Polis. Venezuela: Universidad Bolivariana.

Prieto Sanchís, L. (2009). Sobre el neoconstitucionalismo y sus implicaciones. En Justicia constitucional y derechos fundamentales (pp. 21-135). Madrid: Trotta.

Rival, L. (2015). Transformaciones huaoranis: frontera, cultura y tensión. Quito: Abya-Yala.

Sevilla Buitrago, A. (2015). Capitalist Formations of Enclosure: Space and the Extinction of the Commons. Antipode, 00(0), 1-22. ISSN 0066-4812.

Silveira, M. et al. (2016). Geografías de sacrificio y geografías de esperanza: tensiones territoriales en el Ecuador plurinacional. Journal of Latin American Geography. Monografía de América Latina.

Silveira, M., Bayón M., \& Moreano, M. (2019). Resistencia multiescalar en el Yasuní: aportes desde la geografía crítica. En M. Bayón y N. Torres (Eds.), Geografía crítica para detener el despojo de los territorios: teorías, experiencias y casos de trabajo en Ecuador (pp. 103-115). Quito: Abya-Yala.

Toledo, V. (2005). Políticas indígenas y derechos territoriales en América Latina: 19902004. En Pueblos indígenas, estado y democracia. Buenos Aires: CLACSO.

Wilson, J., Bayón, M., \& Díez, H. (2019). Posneoliberalismo y urbanización plantearia en la Amazonía ecuatoriana. Revista Economía, 67(105), 29-57.

Fecha de envío: 2019/10/30; Fecha de aceptación: 2020/01/14;

Fecha de publicación: 2020/03/0I 